\title{
Removal of Orange 7 Dye from Wastewater Used by Natural Adsorbent of Moringa Oleifera Seeds
}

\author{
Reza Marandi", Seyedeh Marjan Bakhtiar Sepehr
}

\author{
Department of Environmental Engineering, Islamic Azad University, North Tehran Branch, Tehran, Iran
}

\begin{abstract}
Removal of Orange 7 from wastewater using natural adsorbent of Moringa Oleifera seeds were investigated. The effects of some operational parameters such as $\mathrm{pH}$, the amount of biosorbent, initial dye concentration and temperature were examined. The present study revealed optimum conditions for the removal process which included dose of biosorbent $(0.4 \mathrm{~g})$, initial dye concentration $(20 \mathrm{mg} / \mathrm{L})$, initial $\mathrm{pH}(6)$ and temperature $\left(25^{\circ} \mathrm{C}\right)$. The Langmuir and Freundich isotherms were applied for describing the biosorption equilibrium. The process was represented by the Freundich isotherm with a correlation coefficient of 0.94 . The first-order, second-order and intra-particle diffusion kinetic models were implemented for demonstrating the biosorption mechanism and, as a result, intra-particle diffusion kinetics fitted best to the experimental data.
\end{abstract}

Keywords Wastewater, Orange 7, Moringa Oleifera, Biosorption

\section{Introduction}

Among waters, dye wastewater from dyestuff and textile industries is one the most difficult ones to be treated[1]. By absorbing sunlight, dyes can prevent photosynthesis in aqueous ecosystems. Sulfur dyes are harmful to aqueous organisms, since they can rapidly reduce the oxygen content of water[2]. Many studies have been done on physico-chemical methods in order to remove color from textile effluent. These methods include coagulation, oxidization, ultra filtration, electro-chemical, adsorption and combined electro-chemical and adsorption techniques[1-16].

Generally speaking, synthetic dyes' complex aromatic structures make them stable and difficult to biodegrade[17]. Adsorption has some specific benefits, which include treating high-flow wastewaters with good final quality and without producing any harmful substances[2].

Acid Orange 7 [ $p$-(2-hydroxy-1-naphthylazo) benzene sulfonic acid, as a popular water-soluble dye, is used for dyeing a variety of materials such as nylon, aluminum, detergents, cosmetics, wool and silk. Similar to other azo dyes, it is usually disposed in industrial wastewater, which can be considered a serious health threat to humans. It is highly toxic; thus its ingestion can irritate eye, skin, mucous membrane and upper respiratory tract; severe headaches, nausea, water-borne diseases such as dermatitis and loss of bone marrow leading to anemia are also among its harmful consequences. Since it is carcinogenic in nature and leads to

\footnotetext{
* Corresponding author:

r_marandi@iau-tnb.ac.ir (Reza Marandi)

Published online at http://journal.sapub.org/ajee

Copyright (C) 2011 Scientific \& Academic Publishing. All Rights Reserved
}

tumors, it can be fatal to consume it. Current research has found that the electron-with drawing character of the azo group is the main cause of its chronic toxicity, which develops an electron deficiency and is reduced to carcinogenic amino compounds[12].

Since Acid Orange 7 is toxic and carcinogenic by nature, its removal has been attempted by biodegradation and photosensitization on $\mathrm{TiO} 2$ particles. Unfortunately, metabolic intermediates produced after its biodegradation are carcinogenic and photosensitization produces 1,2 - naphthoquinone and phthalic acid during degradation, which are also harmful. Additionally, Biofilm systems have been applied for aerobic nitrification, anoxic denitrification and anaerobic digestionin order to decolorize Acid Orange7[12].

Therefore, it can be concluded that despite its high toxicity, thus far, few attempts have been made to remove Acid Orange 7 from aqueous solutions. Even common chemi$\mathrm{cal} /$ physical methods such as coagulation, flocculation, ozonation, reverse osmosis, electrolysis, ultra-chemical filtration and chemical treatments have not been attempted, which can be attributed to either high solubility of the dye in water or possibility of generating toxic intermediates/products during the process. Furthermore, adsorption, which is influenced by the chemical properties and structure of the dye and also do not produce any toxic products, is deliberately used for the eradication of Acid Orange 7 from waste wate[12].

One of the natural coagulants is the water -soluble extract of the dry seeds of Moringa oleifera, which is a tropical plant from the family of Moringaceae. So far, up to fourteen different species have been identified for it. Moringa oleifera is the most widespread species and grows quickly at low altitudes of the whole tropical belt including arid zones[18]. 
It is drought-tolerant, has nutritional, medicinal and water cleaning attributes and its leaves, flowers, fruits and roots are locally used as food articles. Because of its medical and therapeutic properties, it is applied as a cure for different ailments and diseases and physiological disorders in eastern allopathic medicine.

The present investigation aims at examining the sorption potential of SMOS in order to remove organics from aquous media[19].

Table 1-1. Chemical stucture and general properties of Acid Orange 7.

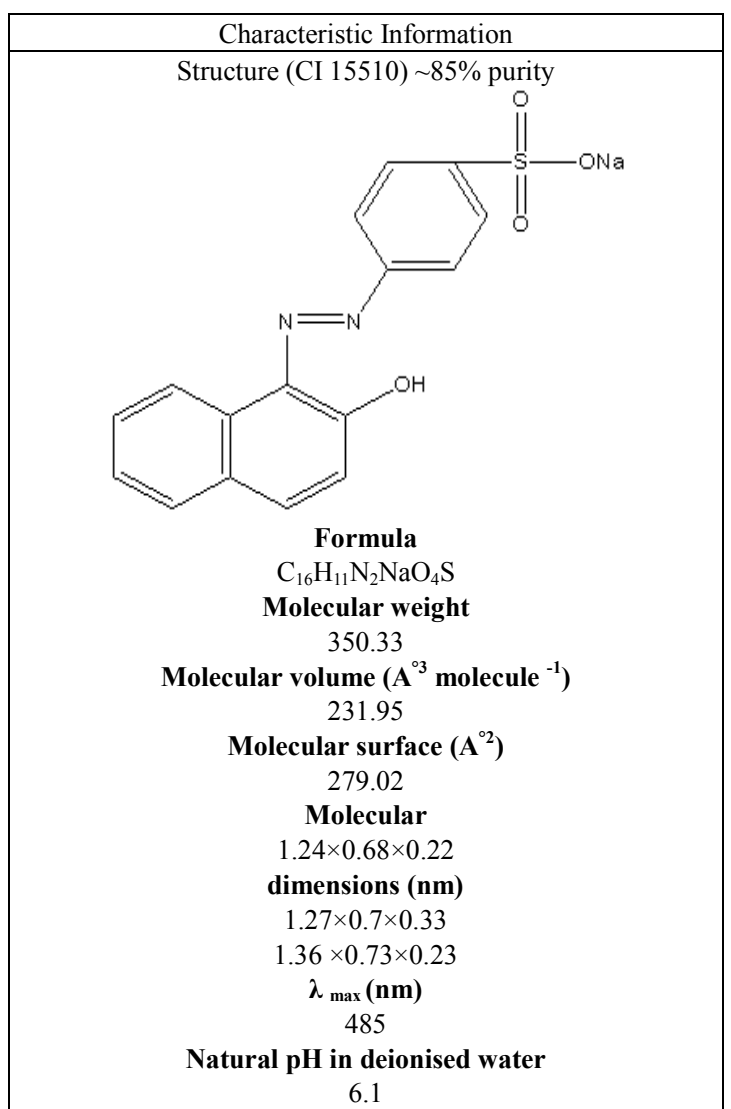

M. oleifera prefers hot, semi-arid regions (annual rainfall $250-1500 \mathrm{~mm}$ ); thus it grows widely throughout the tropics. Furthermore, it is suitable for lowland cultivation at altitudes less than $600 \mathrm{~m}$. This tree is tolerant of light frosts and slightly alkaline soils up to $\mathrm{pH}$ 9. Its seeds which posess effective coagulation properties are quite efficient in reducing turbidity, micro-organisms of wastewaters and also in sludge conditioning. The active agents of coagulation are dimeric cationic proteins with the molecular weight of approximately $13(\mathrm{kDa})$ with an isoelectric point between 10 and $11[20]$.

Coagulation's active component in Moringa oleifera is supposed to remove the suspended solids in wastewater by the sweep coagulation mechanism[20].

Moringa oleifera, as a tropical plant who can survive heat, desiccating dryness and destitute soils, is abundantly available throughout the year. Its various parts are used for innumerable pharmacological properties viz. antimicrobial activity, analgesic activity and antihypertensive activity.
Coagulating behavior of its seed powder has been studied for different aspects of water treatment like turbidity, alkalinity, total dissolved solids and hardness[21].

\section{Materials and Methods}

\subsection{Instruments}

1-METTLER balance with accuracy $0.0001 \mathrm{~g}$

2-EDT Instruments $\mathrm{pH}$ meter

3-Sigma 301 centrifuge

4-GFL 3005 Shaker

5- Heidolph unimax 1010 Shaker Incubator

6- unico $4802 \mathrm{UV}-\mathrm{V}$ is spectrophotometer

\subsection{Preparing Acid Orange 7 and Biosorption Capacity}

The Acid Orange 7 used in this study was obtained from Merck and Stock AO7 solution $(500 \mathrm{mg} / \mathrm{L})$ was prepared by dissolving $0.05 \mathrm{~g}$ of AO7 in $10 \mathrm{~mL}$ of double-distilled water and diluting quantitatively to $100 \mathrm{~mL}$. AO7 solutions of different concentrations $(2.5-50 \mathrm{mg} / \mathrm{L})$ were prepared by the adequate dilution of the stock solution to $250 \mathrm{~mL}$. The applied glassware was rinsed several times with double-distilled water before being used. The absorbance of standard $\mathrm{AO} 7$ solutions was measured and plotted against the concentration.

In brief, batch experiments were carried out as functions of biomass dose $(0.05-1.0 \mathrm{~g})$, dye concentration (2.5-50 $\mathrm{mg} / \mathrm{L}), \mathrm{pH}(3.0-9.0)$, temperature $\left(10-30^{\circ} \mathrm{C}\right)$ and contact time (1-60 min). Known solutions of $\mathrm{AO} 7$ were poured into separate $100 \mathrm{ml}$ Erlenmeyer flasks. After $\mathrm{pH}$ adjustment, a known quantity of biosorbent was added and, at last, dye bearing suspensions were kept on the shaker (250 RPM) for 60 minutes at the temperature. The samples were taken from 0 to 60 minutes and the biomass was separated from the solutions by centrifuge and was subjected to dye estimation by UV/Vis spectrophotometry. Dye concentrations were recorded before and after biosorption. Removal efficiency was computed by the following equation[19]:

$$
\% R=\frac{C_{0}-C_{t}}{C_{0}} \times 100
$$

where $C_{0}(\mathrm{mg} / \mathrm{L})$ and $C_{\mathrm{t}}(\mathrm{mg} / \mathrm{L})$ are initial and residual concentrations of dye, respectively.

\subsection{Analytical Methods}

Maximum absorbance wavelength of $\mathrm{AO} 7$ was determined experimentally. The concentration of $\mathrm{AO} 7$ in the solutions before and after the equilibrium was determined by $\mathrm{UV} / \mathrm{V}$ is spectrophotometry at a $\lambda_{\max }$ of $485 \mathrm{~nm}$, using a unico $4802 \mathrm{UV} / \mathrm{Vis}$ spectrophotometer. $\mathrm{pH}$ of the solutions was measured by a EDT Instruments $\mathrm{pH}$ meter. $\mathrm{NaOH}$ and $\mathrm{HCl}$ were obtained from Merck, Germany. Dilute solutions of $\mathrm{NaOH}$ and $\mathrm{HCl}$ were prepared and used for adjusting the pH.All the chemicals used in this study were of analytical reagent grade. 


\section{Results and Discussion}

To acquire a comprehensive understanding of biosorption of $\mathrm{AO} 7$ onto SMOS, a meticulous investigation of effective parameters was carried out. Prior knowledge on the optimal conditions provides a better design and modeling which are, therefore, of vital importance for exploiting the potentiality of the SMOS biosorbent[19]. The biosorption of AO7 onto SMOS is influenced by the sorbent dose, concentration of sorbate, initial $\mathrm{pH}$, reaction temperature and contact time.

\subsection{Effect of Biosorbent Dose}

A number of investigations were carried out by varying the amount of SMOS from 0.05 to $1.0 \mathrm{~g}$ at the fixed initial dye concentration of $20 \mathrm{mg} / \mathrm{L}, \mathrm{pH}$ of 7 and room temperature of $25 \pm 1{ }^{\circ} \mathrm{C}$. These studies showed an increase in biosorption with the increase in the dose of biosorbent (Fig.3-1). Optimum biosorbent dose was found to be $0.4 \mathrm{~g}$.

\subsection{Effect of Initial Dye Concentration}

Fig.3-2, show the results of experiments conducted in the range of dye concentration $(2.5-50 \mathrm{mg} / \mathrm{L})$ at the constant biosorbent dose $(0.2 \mathrm{~g}), \mathrm{pH}(7)$ and temperature $\left(25^{\circ} \mathrm{C}\right)$. The obtained results reveal that percent removal of dye depends on the initial dye concentration. The obtained optimum dye concentration was $20 \mathrm{mg} / \mathrm{L}$. These observations can be explained by the fact that sufficient biosorption sites are available for accommodating an increasing number of dye molecules. In other words, the number of molecules available for sorbing onto the sorbent surface is relatively lower in comparison with the ones available for biosorption sites[19,24]. Higher dye concentrations are capable of affecting the chemical equilibrium between dye molecules in the liquid phase and the ones adsorbed onto the biosorbent surface resulting in a further biosorption process. Moreover, this sorption behavior can be attributed to higher chance of effective interaction between adsorbate molecules and biosorbent surface as the concentration of dye increases. These findings demonstrate the applicability and efficacy of SMOS for the removal of $\mathrm{AO} 7$ dye from the aqueous media.

\subsection{Effect of Initial pH}

Effect of initial $\mathrm{pH}$ on the biosorption process was monitored in the $\mathrm{pH}$ range of 3 and 9 at the biosorbent dose of 0.20 $\mathrm{g}$, initial dye concentration of $20 \mathrm{mg} / \mathrm{L}$ and temperature of $25 \pm 1{ }^{0} \mathrm{C}$ (Fig.3-3). The most appreciable biosorption was found in $\mathrm{pH}$ 6. Variation in the removal of $\mathrm{AO} 7$ with respect to $\mathrm{pH}$ can be explained by considering surface properties of biosorbent material and ionization state of AO7[24]. Protaineous amino acids are mainly considered as the active functional compounds present in shelled Moringa Oleifera seeds. These amino acids have a variety of structurally $\mathrm{pH}$-dependent properties and the ability to generate negatively charged atmosphere.

\subsection{Effect of Temperature}

Effect of temperature over the ranges 10,25 and $30^{\circ} \mathrm{C}$ on AO7 biosorption was examined under the conditions of 0.20 $\mathrm{g}$ biosorbent dose, $20 \mathrm{mg} / \mathrm{L}$ dye concentration and the initial $\mathrm{pH}$ of 7. The biosorption was fast at the beginning of the experiment. The sensitivity of biosorption process toward temperature is presented in Fig.3-4. This figure exhibits a small fluctuation in the percent sorption of dye as temperature increases from $10^{\circ} \mathrm{C}$ to $25^{\circ} \mathrm{C}$ and decreases from $25^{\circ} \mathrm{C}$ to $30^{\circ} \mathrm{C}$.

\subsection{Effect of Contact Time}

The variation in the sorption of $\mathrm{AO} 7$ as a function of contact time is presented in Fig. 3-5. The results obtained under constant conditions of $0.20 \mathrm{~g}$ biosorbent dose, $20 \mathrm{mg} / \mathrm{L}$ initial dye concentration, $\mathrm{pH}$ of 7 and room temperature of $25 \pm 1{ }^{0} \mathrm{C}$ reveal that the percent removal of $\mathrm{AO} 7$ rises as time proceeds. The sorption is quite rapid initially, then slows down gradually and, finally, levels out and reaches a maximum dye removal. This trend may be attributed to the elevation of contact between the sorbate and sorbent during the experiment. Interestingly, near $60 \%$ of the ultimate biosorption occurred within first 5 minutes of contact. Bearing in mind the time restraints in the practice, it is recommended that SMOS be capable of being used as an effective pretreatment technology in the dye wastewater treatment.

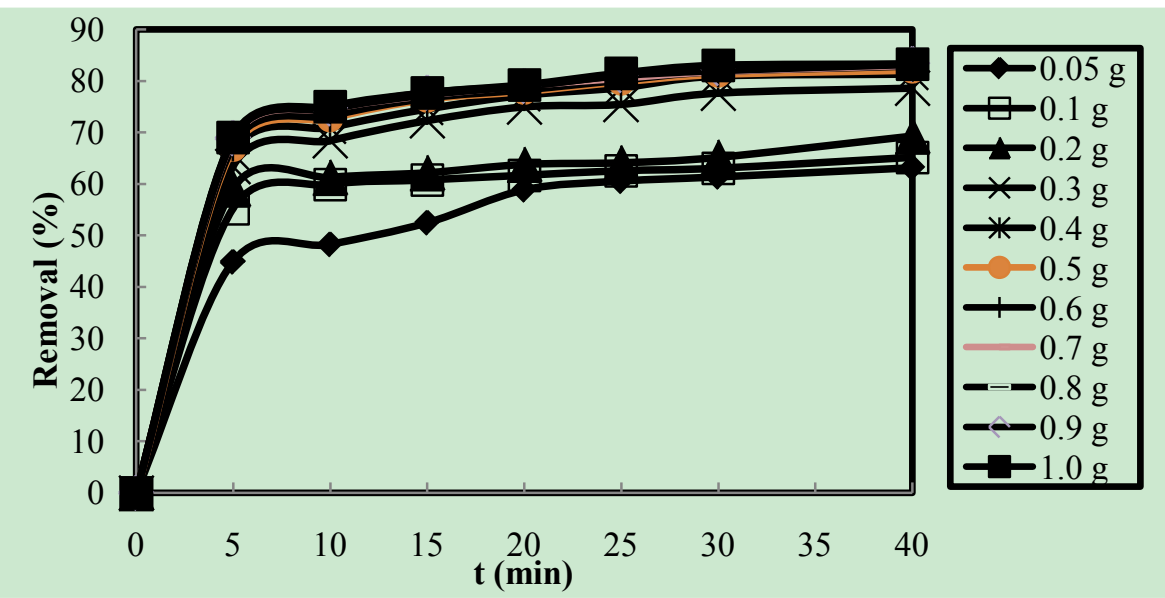

Figure 3-1. Effect of biosorbent dose on the removal of $A O 7$ using $\mathrm{SMOS}$ at $\mathrm{C}_{0}=20 \mathrm{mg} / \mathrm{L}, \mathrm{pH}=7$ and $\mathrm{T}=25^{\circ} \mathrm{C}$. 


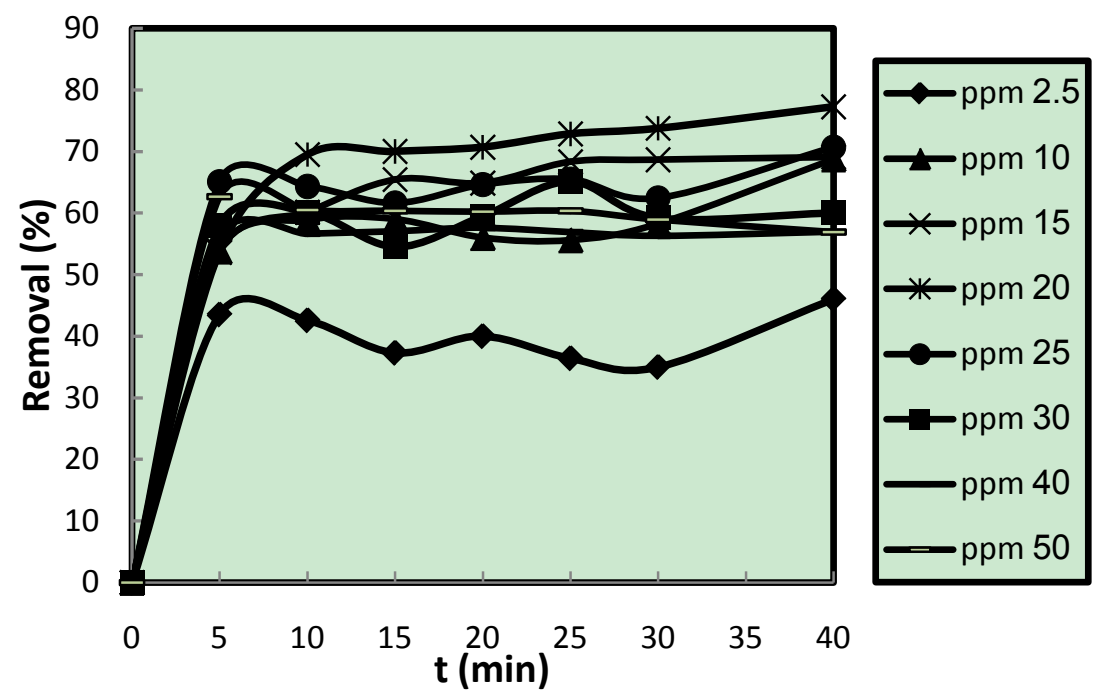

Figure 3-2. Effect of initial dye concentration on the biosorption behavior of $\mathrm{AO} 7$ on $\mathrm{SMOS}$ at $\mathrm{m}=0.2 \mathrm{~g}, \mathrm{pH}=7$ and $\mathrm{T}=25^{\circ} \mathrm{C}$.

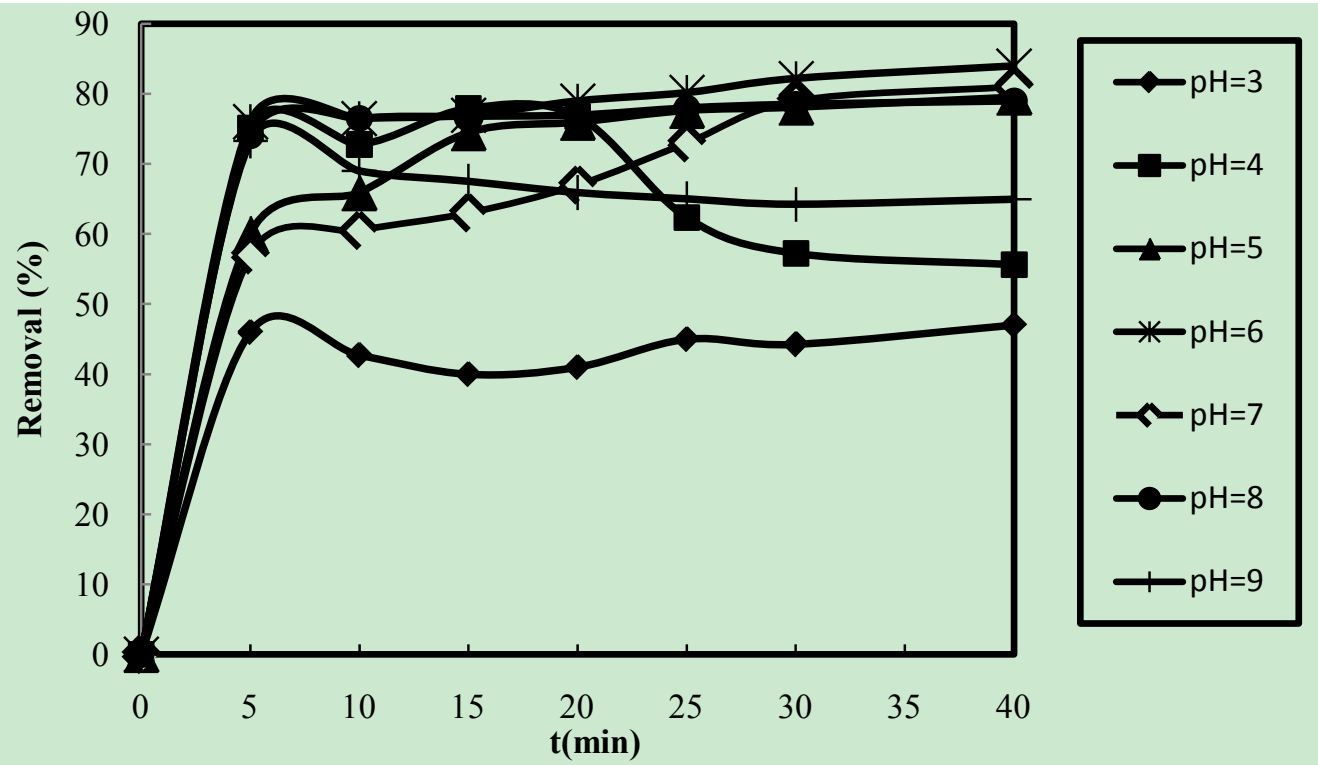

Figure 3-3. Effect of varying initial $\mathrm{pH}$ on the removal of $\mathrm{AO} 7$ by SMOS at $\mathrm{m}=0.20 \mathrm{~g}, \mathrm{C}_{0}=20 \mathrm{mg} / \mathrm{L}$ and $\mathrm{T}=25^{\circ} \mathrm{C}$.

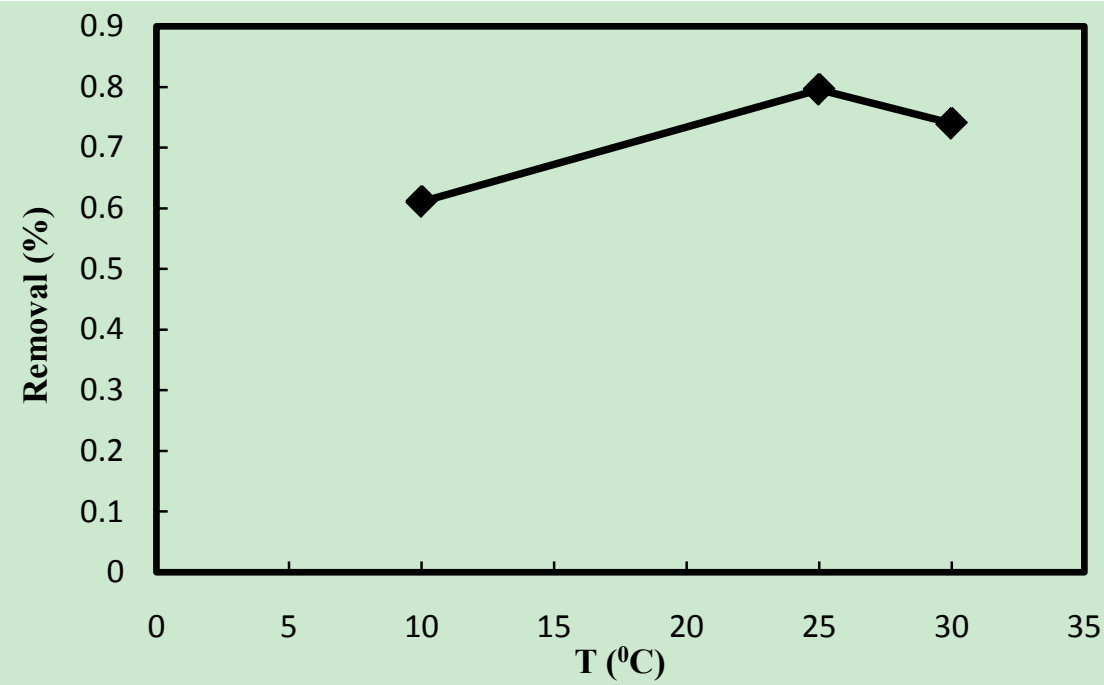

Figure 3-4. Effect of different temperatures on the biosorption of $\mathrm{AO} 7$ by SMOS at $\mathrm{m}=0.20 \mathrm{~g}, \mathrm{C}_{0}=20 \mathrm{mg} / \mathrm{L}$ and $\mathrm{pH}=7$. 


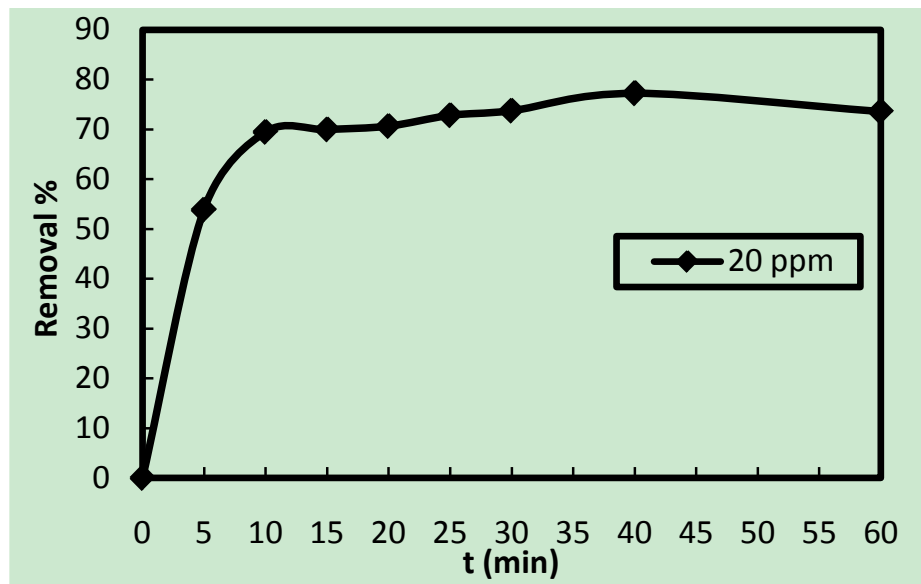

Figure 3-5. Effect of contact time on the removal of $\mathrm{AB} 9$ using $\mathrm{SMOS}$ at $\mathrm{m}=0.40 \mathrm{~g}, \mathrm{C}_{0}=20 \mathrm{mg} / \mathrm{L}, \mathrm{pH}=7$ and $\mathrm{T}=25^{\circ} \mathrm{C}$.

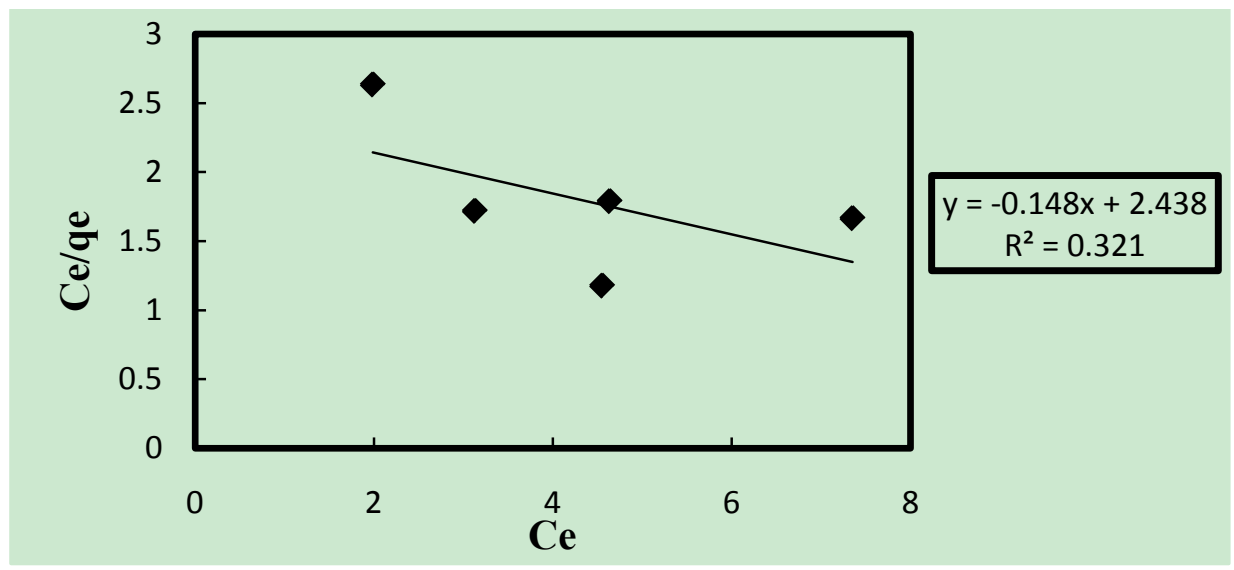

Figure 3-6. Langmuir isotherm chart.

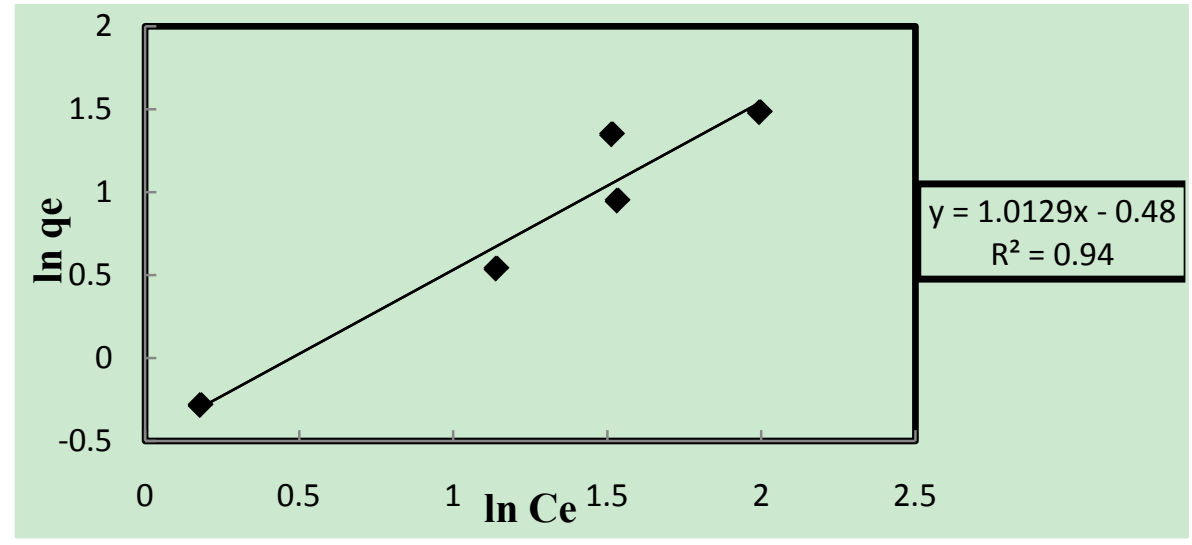

Figure 3-7. The Freundlich isotherm's chart.

\subsection{Adsorption Isotherm}

In order to understand the adsorption process, the Langmuir and Freundlich isotherms, Figs. 3-6 and 3-7, respectively, were used to represent the equilibrium relationship for different initial Acid Orange 7 concentrations' experiments. The Langmuir equation assumes that adsorption is limited to monolayer; its linearized form can be represented as:

$$
\frac{C_{e}}{q_{e}}=\frac{1}{q_{\max }} C_{e}+\frac{1}{b \cdot q_{\max }}
$$

where qe is the metal ion sorbed $(\mathrm{mg} / \mathrm{g})$, Ce equilibrium concentration of dye solution and $\mathrm{q}_{\max }$ and $\mathrm{b}$ Langmuir constants.

The Freundlich equation is an empirical relationship which describes the adsorption of the solutes from a liquid to solid surface. Linearized form of the Freundlich equation is as follows:

$$
\ln q_{e}=\frac{1}{n} \ln C_{e}+\ln K_{f}
$$

where qe is the metal ion sorbed $(\mathrm{mg} / \mathrm{g})$, Ce equilibrium concentration of metal ion solution $(\mathrm{mg} / \mathrm{L})$ and $\mathrm{K}_{\mathrm{f}}$ and $1 / \mathrm{n}$ constants.

As indicated in Table 3-2, the coefficients of determina- 
tion $\left(\mathrm{R}^{2}\right)$ of the Freundlich model are greater than 0.9 and close to one, which indicates that the Freundlich model adequately describes the experimental data of these dye biosorption experiments[21].

Table3-1. Results of Langmuir isotherm.

\begin{tabular}{|c|c|c|c|}
\hline $\mathrm{C}_{0}$ & $\mathrm{C}_{\mathrm{e}}$ & $\mathrm{q}_{\mathrm{e}}$ & $\mathrm{C}_{\mathrm{e}} / \mathrm{q}_{\mathrm{e}}$ \\
\hline $\mathrm{ppm} 5$ & $1.985 \mathrm{ppm}$ & 0.75375 & 2.633 \\
\hline $\mathrm{ppm} \mathrm{10}$ & $3.126 \mathrm{ppm}$ & 1.7185 & 1.7185 \\
\hline $15 \mathrm{ppm}$ & $4.6335 \mathrm{ppm}$ & 2.59 & 1.7889 \\
\hline $20 \mathrm{ppm}$ & $4.55 \mathrm{ppm}$ & 3.8625 & 1.1781 \\
\hline $\mathrm{ppm} \mathrm{25}$ & $7.35 \mathrm{ppm}$ & 4.4125 & 1.6657 \\
\hline
\end{tabular}

Table 3-2. Constants of Langmuir isotherm.

\begin{tabular}{|c|c|c|}
\hline $\mathrm{q}_{\max }$ & $\mathrm{b}$ & $\mathrm{R}^{2}$ \\
\hline-6.75 & -0.06 & 0.3217 \\
\hline
\end{tabular}

Table 3-3. Results of the Freundlich isotherm.

\begin{tabular}{|c|c|c|c|c|}
\hline $\mathrm{C}_{0}$ & $\mathrm{C}_{\mathrm{e}}$ & $\mathrm{q}_{\mathrm{e}}$ & $\ln \mathrm{q}_{\mathrm{e}}$ & $\ln \mathrm{C}_{\mathrm{e}}$ \\
\hline $5 \mathrm{ppm}$ & $1.198 \mathrm{ppm}$ & 0.75375 & -0.282 & 0.18 \\
\hline $10 \mathrm{ppm}$ & $3.126 \mathrm{ppm}$ & 1.545 & 0.435 & 1.34 \\
\hline $15 \mathrm{ppm}$ & $4.633 \mathrm{ppm}$ & 2.59 & 0.951 & 1.533 \\
\hline $20 \mathrm{ppm}$ & $4.55 \mathrm{ppm}$ & 3.8625 & 1.3513 & 1.5151 \\
\hline $25 \mathrm{ppm}$ & $7.35 \mathrm{ppm}$ & 4.4125 & 1.484 & 1.9947 \\
\hline
\end{tabular}

Table 3-4. Constants of Freundlich isotherm.

\begin{tabular}{|c|c|c|}
\hline $\mathrm{K}_{\mathrm{f}}$ & $\mathrm{n}$ & $\mathrm{R}^{2}$ \\
\hline 0.61878 & 0.987 & 0.94 \\
\hline
\end{tabular}

\subsection{Kinetic Studies}

In order to evaluate the kinetics of $\mathrm{AO} 7$ biosorption onto SMOS, three models were applied, i.e. first-order model, second-order model and intra-particle diffusion model. The linear form of the first-order model can be formulated as:

$$
\ln C_{t}-\ln C_{0}=-k_{1} t
$$

The second-order linear equation can be written as:

$$
\frac{1}{C_{t}}-\frac{1}{C_{0}}=k_{2} t
$$

Film resistance plays an important role in the overall transport of the solute. In order to estimate the intra-particle diffusion rate, Morris-Weber equation was also subjected to sorption kinetic data in the following way[25]:

$$
q_{t}=k_{i} t^{1 / 2}
$$

where $q_{\mathrm{t}}(\mathrm{mg} / \mathrm{g})$ is the amount of dye adsorbed per unit mass of biosorbent at time $t, C_{0}(\mathrm{mg} / \mathrm{L})$ represents initial concentration of adsorbate in the solution, $C_{\mathrm{t}}(\mathrm{mg} / \mathrm{L})$ is the concentration of adsorbate in the solution at time $t$, time is represented by $t(\mathrm{~min})$ and $k_{1}\left(\mathrm{mg} \cdot \mathrm{L}^{-1} \cdot \mathrm{min}^{-1}\right), k_{2}\left(\mathrm{mg}^{-1}\right.$. L. $\left.\mathrm{min}^{-1}\right)$ and $k_{\mathrm{i}}\left(\mathrm{mg} \cdot \mathrm{g}^{-1} \cdot \mathrm{min}^{-1 / 2}\right)$ stand for rate constants of the first-order, second-order and intra-particle diffusion models, respectively. $q_{\mathrm{t}}$ is obtained from the following equation:

$$
q_{t}=\frac{\left(C_{0}-C_{t}\right) V}{m}
$$

where $V(\mathrm{~L})$ represents the volume of solution and $m(\mathrm{~g})$ is the biosorbent mass. The applicability of each model was studied by plotting $\left(\ln C_{\mathrm{t}}-\ln C_{0}\right)$ against $t,\left(1 / C_{\mathrm{t}}-1 / C_{0}\right)$ against $t$ and $q_{\mathrm{t}}$ against $t^{1 / 2}$ for the first-order, second order, and intra-particle diffusion models, respectively.

If $q_{t}$ is plotted against $t^{1 / 2}$, the sorption data yields a straight line. This observation indicates that kinetics of AO7 dye sorption computed from the slope of linear plots onto SMOS surface follows the linearity in the range of 5-40 min, as shown in Fig. 3-8[25].

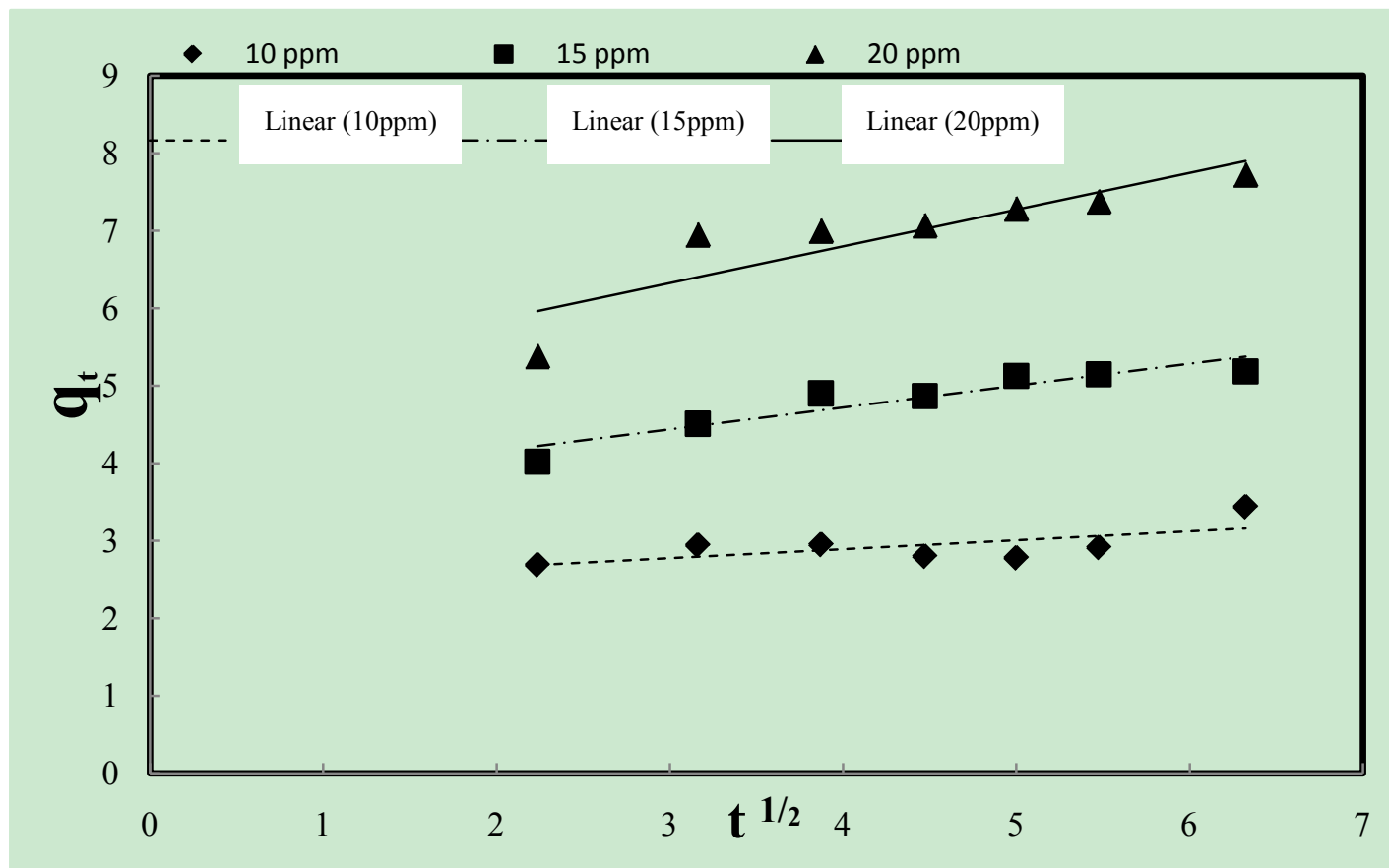

Figure 3-8. The intra-particle diffusion kinetic plots for the biosorption of AO7 dye by SMOS at different initial dye concentrations, $0.2 \mathrm{~g}$ biosorbent dose, $\mathrm{pH} 7$ and $25^{\circ} \mathrm{C}$. 


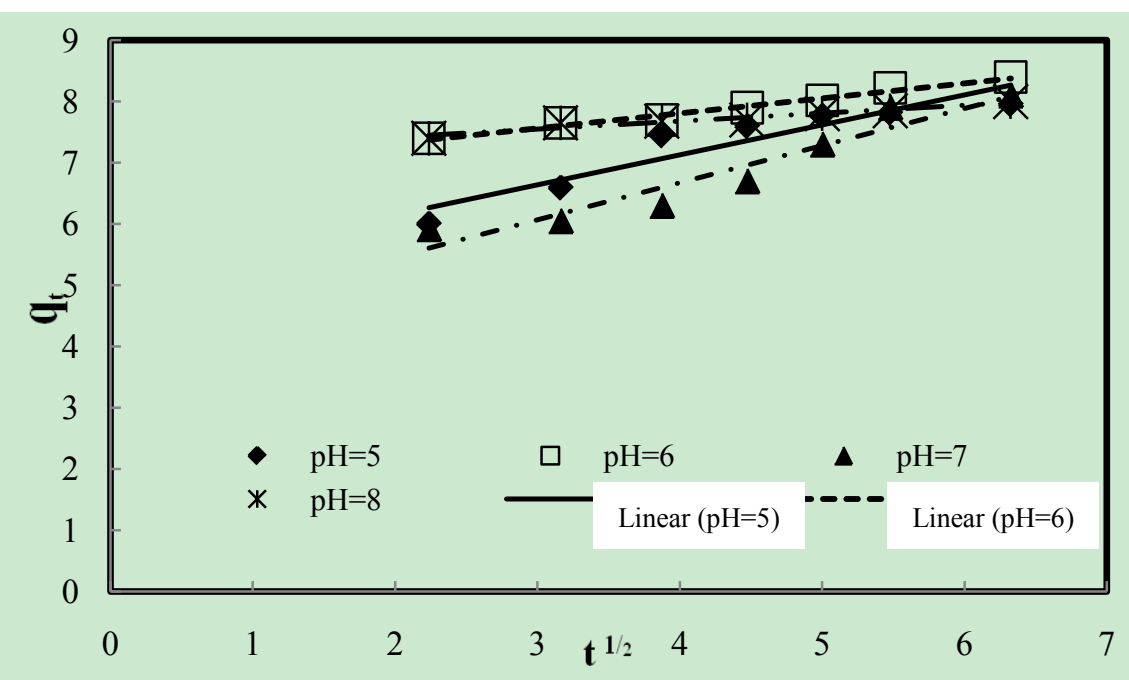

Figure 3-9. The intra-particle diffusion kinetic plots for the biosorption of AO7 dye by SMOS at different initial pH, $20 \mathrm{mg} / \mathrm{L}$ initial dye concentration, 0.2 g biosorbent dose and $25^{\circ} \mathrm{C}$.

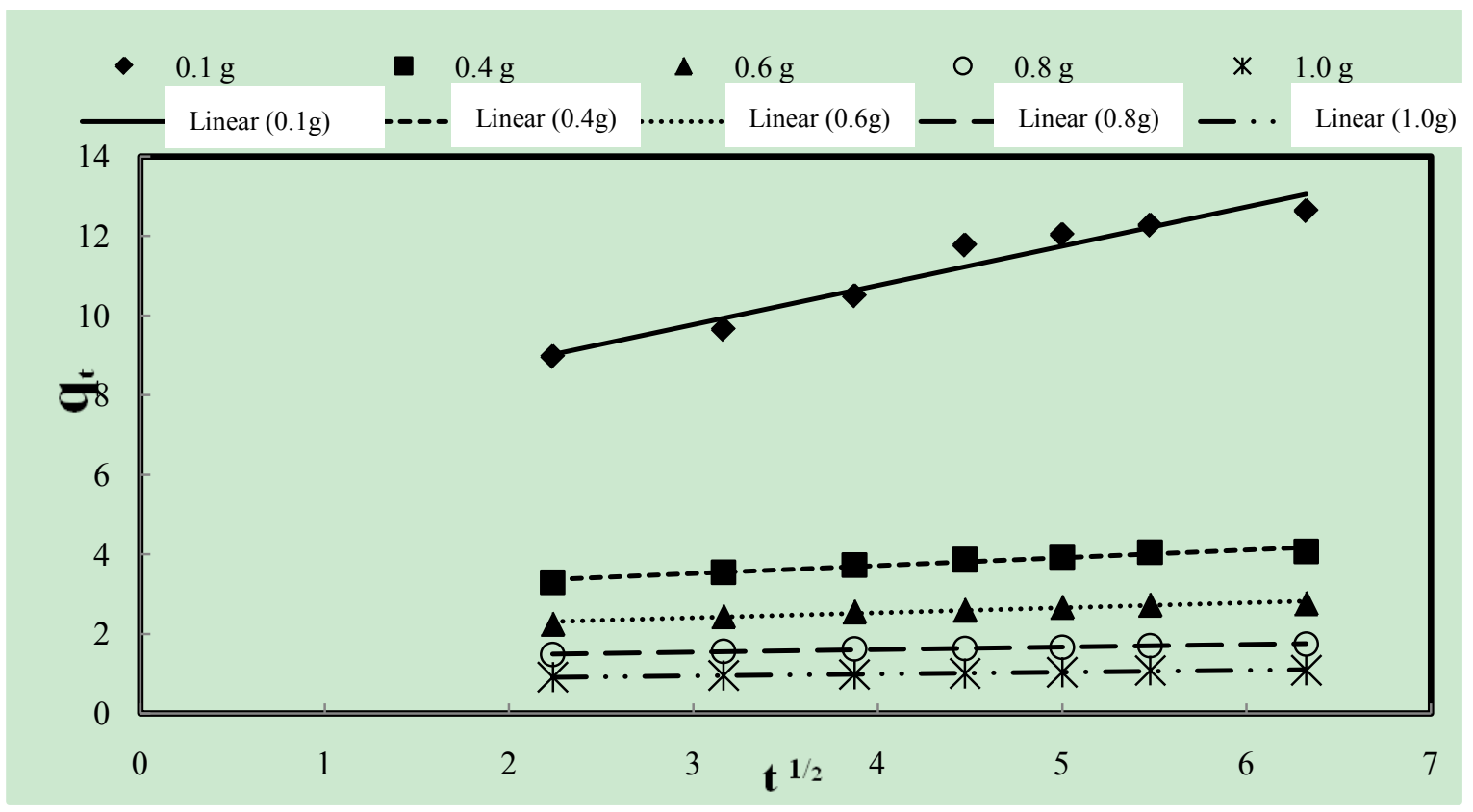

Figure 3-10. The intra-particle diffusion kinetic plots for biosorption of AO7 dye by SMOS at different biosorbent doses, $20 \mathrm{mg} / \mathrm{L}$ initial dye concentration, $\mathrm{pH} 7$ and $25^{\circ} \mathrm{C}$.

Biosorption kinetics was monitored very carefully in various biosorbent doses, initial pollutant concentrations and initial $\mathrm{pH}$. Correlation coefficients and rate constants obtained from the slopes of the corresponding linear plots are tabulated in Tables 3-5,3-6 and 3-7. The results suggest that the sorption phenomenon follows kinetics intra-particle diffusion at relatively low temperature levels. Correlation coefficients were found closer to unity in the model's intra-particle diffusion in comparison with the first-order and second-order models in the whole initial dye concentration range. Therefore, for different initial dye concentrations, the kinetics could be explained by the intra-particle diffusion kinetic model. Intra-particle diffusion kinetics also fitted best to the experimental data at both high biosorbent doses and little acidic $\mathrm{pH}$.
Table 3-5. Kinetics of biosorption of AO7 dye by shelled Moringa Oleifera seeds. Rate constant and correlation coefficients for three kinetic models at different biosorbent doses.

\begin{tabular}{|c|c|c|c|c|c|c|}
\hline & \multicolumn{2}{|c|}{ First order } & \multicolumn{2}{c|}{ Second order } & \multicolumn{2}{l|}{$\begin{array}{l}\text { Intra-particle diffu- } \\
\text { sion }\end{array}$} \\
\hline $\mathrm{m}(\mathrm{g})$ & $K_{I}$ & $R^{2}$ & $K_{2}$ & $R^{2}$ & $K_{i}$ & $R^{2}$ \\
\hline 0.05 & 0.0049 & 0.7348 & 0,0006 & 0.7032 & 0.7247 & 0.8358 \\
\hline 0.1 & 0.0126 & 0.8052 & 0.0014 & 0.9274 & 0.9849 & 0.9454 \\
\hline 0.2 & 0.0059 & 0.8395 & 0.0008 & 0.8674 & 0.2083 & 0.9019 \\
\hline 0.3 & 0.014 & 0.7452 & 0.0029 & 0.9315 & 0.2519 & 0.9441 \\
\hline 0.4 & 0.0176 & 0.9113 & 0.0036 & 0.945 & 0.1968 & 0.9517 \\
\hline 0.5 & 0.0172 & 0.90 & 0.0037 & 0.9448 & 0.1494 & 0.9352 \\
\hline 0.6 & 0.0181 & 0.93 & 0.004 & 0.9634 & 0.1257 & 0.9521 \\
\hline 0.7 & 0.0172 & 0.9161 & 0.0038 & 0.9582 & 0.0979 & 0.9408 \\
\hline 0.8 & 0.0082 & 0.9488 & 0.0012 & 0.9637 & 0.0634 & 0.9748 \\
\hline 0.9 & 0.0074 & 0.9461 & 0.001 & 0.9669 & 0.0553 & 0.9485 \\
\hline 1.0 & 0.0052 & 0.9456 & 0.0005 & 0.9521 & 0.0456 & 0.9702 \\
\hline
\end{tabular}


Table 3-6. Kinetics of biosorption of AO7 dye by shelled Moringa Oleifera seeds (Rate constant and correlation coefficients for three kinetic models at different initial dye concentrations).

\begin{tabular}{|c|c|c|c|c|c|c|}
\hline & \multicolumn{2}{|c|}{ First order } & \multicolumn{2}{c|}{ Second order } & \multicolumn{2}{c|}{$\begin{array}{c}\text { Intra-particle } \\
\text { diffusion }\end{array}$} \\
\hline $\begin{array}{c}\mathrm{C}_{0} \\
\mathrm{pp} \\
\mathrm{m})\end{array}$ & $K_{l}$ & $R^{2}$ & $K_{2}$ & $R^{2}$ & $K_{i}$ & $R^{2}$ \\
\hline 2.5 & 0.0002 & 0.0009 & 0.0002 & 0.0025 & 0.003 & 0.0095 \\
\hline 5 & 0.0016 & 0.0175 & 0.0005 & 0.0061 & 0.022 & 0.047 \\
\hline 10 & 0.0077 & 0.5095 & 0.0021 & 0.5181 & 0.1154 & 0.4393 \\
\hline 15 & 0.011 & 0.7946 & 0.002 & 0.825 & 0.282 & 0.8698 \\
\hline 20 & 0.016 & 0.7731 & 0.0026 & 0.85 & 0.472 & 0.7759 \\
\hline 25 & 0.0041 & 0.3195 & 0.0005 & 0.3358 & 0.1159 & 0.197 \\
\hline 30 & 0.0022 & 0.1034 & 0.0002 & 0.1084 & 0.1197 & 0.1251 \\
\hline 40 & 0.0003 & 0.1063 & 0.0002 & 0.079 & 0.029 & 0.1568 \\
\hline 50 & 0.0033 & 0.8732 & 0.0002 & 0.5367 & 0.286 & 0.8404 \\
\hline
\end{tabular}

Table 3-7. Kinetics of biosorption of $\mathrm{AO} 7$ dye by shelled Moring Oleifera seeds (Rate constant and correlation coefficients for three kinetic models at different initial $\mathrm{pH})$.

\begin{tabular}{|l|l|l|l|l|l|l|}
\hline & \multicolumn{2}{|l|}{ First order } & \multicolumn{2}{l|}{ Second order } & \multicolumn{2}{l|}{$\begin{array}{l}\text { Intra-particle } \\
\text { diffusion }\end{array}$} \\
\hline $\begin{array}{l}\mathrm{p} \\
\mathrm{H}\end{array}$ & $K_{I}$ & $R^{2}$ & $K_{2}$ & $R^{2}$ & $K_{i}$ & $R^{2}$ \\
\hline 3 & 0.0015 & 0.1539 & 0.0001 & 0.1366 & 0.049 & 0.0701 \\
\hline 4 & 0.0226 & 0.7539 & 0.0032 & 0.6459 & 0.06005 & 0.7061 \\
\hline 5 & 0.0187 & 0.8218 & 0.0033 & 0.8723 & 0.4895 & 0.8739 \\
\hline 6 & 0.0066 & 0.684 & 0.0028 & 0.9561 & 0.2454 & 0.9808 \\
\hline 7 & 0.0233 & 0.9048 & 0.0046 & 0.9355 & 0.6062 & 0.9191 \\
\hline 8 & 0.0055 & 0.8724 & 0.0009 & 0.8897 & 0.1304 & 0.9446 \\
\hline 9 & 0.004 & 0.6583 & 0.0011 & 0.6733 & 0.02094 & 0.8448 \\
\hline
\end{tabular}

\section{Conclusions}

Successful application of shelled Moringa Oleifera Lamarck seeds as a biosorbent at the laboratory scale introduces an effective, feasible and environmentally-friendly method for removing C.I. Acid Orange 7 from the aqueous systems. The biosorption process was found to be dependent on biosorbent dose, initial dye concentration, initial $\mathrm{pH}$, temperature and contact time. Under the studied conditions, biosorption equilibrium data followed Freundlich isotherm more favorably than Langmuir isotherm. The values of $1 / n$ and $K_{f}$ from Freundlich and Langmuir isotherms confirmed the effectiveness of SMOS biosorbent for removing AO7 dye at low concentrations. Batch biosorption capacity tests have shown that intra-particle diffusion kinetics can be applied for describing the biosorption mechanism in certain conditions, whereas the first-order and second-order models with little differences did not fit the experimental data. The removal of Acid Orange 7 was observed to be rapid at the primary stages of biosorption process. The main conclusion is that the shelled Moringa Oleifera seeds demonstrate an adequate potential for being exploited as an economically viable and indigenous pretreatment approach in modern technology of wastewater treatment. Future investigations should be conducted with a view to selectively separating the present dye contaminants, regenerating the exhausted biomass, recovering the sorbed dye and designing to continuous dye treatment systems. These studies can further ameliorate the economic aspects of dye wastewater treatment.

\section{REFERENCES}

[1] Padmesh, T.V.N., Vijayaraghavan, K., Sekaran, G., Velan, M., 2005, Batch and column studies on biosorption of acid dyes on fresh water macro alga Azolla filiculoides, J. Haz. Mat., B125, PP.121-129

[2] Aber, S., Daneshvar, N., Soroureddin, S.M., 2007, Study of acid orange 7 removal from aqueous by powered activated carbon of experimental results by artificial neural network, Desalination, 211, PP.87-95

[3] Gupta, V.K., Suhas, 2009, Application of low-cost adsorbents for dye removal - A review, Journal of Enviromental Management, 90, PP.2313-2342

[4] Aksu, Z., 2005, Application of biosorption for the removal of organic pollutant: a review, Process Biochemistry, 40, PP.997-1026

[5] Ozer, A., Gonul, A., Turabik, M, 2006, The removal of Acid Red 274 from wastewater: Combined biosorption and biocoagulation with Spirogyra rhizopus, Dyes and Pigments, 71, pp. $83-89$

[6] Gao, J., Zhang, Q., Chen, R., Peng, Y., 2009, Biosorption of Acid Yellow 17 from aqueous solution by non-living aerobic granular sludge, Jounal of Hazardous Materials, 10612, No. of Pages 11

[7] Al-Degs, Y., El-Barghouthi, m., El-Sheikh, A.H., Walker, G., 2008, Effect of solution $\mathrm{pH}$, ionic strength, and temperature on adsorption behavior of reactive dyes on activated carbon, Dyes and Pigments, 77, PP.16-23

[8] Moussavi, Gh., Mahmoudi, M., 2009, Removal of azo and anthraquinon reactive dyes from industrial wastewaters using $\mathrm{MgO}$ nanoparticles, Jounal of Hazardous Materials, 168, pp.806-812

[9] Silva, J. P., Sousa, S., Rodrigues, J., 2004, Adsorption of acid orange 7 dye in aqueous solution by spent grains, Separation and Purification Technology, 40, PP.309-315

[10] Cheung, W. H., Szeto, Y. S., Mckey, G., 2009, Enhancing the adsorption capacities of acid dyes by chitosan nano particles, Bioresource Technology, 100, PP.1143-1148

[11] Ji, P., Zhang, J., Chen, feng, Anpo, M., 2009, Study of adsorption and degradation of acid orang 7 on the surface of $\mathrm{CeO}_{2}$ under visibile light irradiation, Applied Catalysis B: Environmental, 85, PP.148-154

[12] Gupta, V. K., Mittal, A., Gajbe , V., Mittal, J., 2006, Removal and Recovery of the Hazardous Azo Dye Acid Orange 7 through Adsorption over Waste Materials: Bottom Ash and De-Oiled Soya, Ind. Eng. Chem., 45, PP.1446-1453

[13] Tung Lin, Y., Huang Weng, Ch., Ying Chen, F., 2008, Effective removal of AB24 dye by nano/micro-size zero-valent iron, Separation and Purification Technology, 64, PP. 26-30

[14] Gonzalez, M. P. E., Montoya, V. H., 2009, Removal of acid orange 7 by guava seed carbon: A four parameter optimiza- 
tion study, J. Haz. Mat., 168, PP.515-522

[15] Silva, J. P., Sousa, S., Rodrigues, J., Antunes, H., 2004, Adsorption of acid orange 7 dye in aqueous solutions by spent brewery grains, Separation and Purification Technology, 40, PP.309-315

[16] Mahony, T. O., Guibal, E., Tobin, J. M., 2002, Reactive dye biosorption by Rhizopus arrhizus biomass, Enzayme and Technology, 31, PP.456-463

[17] Meia, H. Ch., Chienb, Ch. T., Dec, P. S., Lungd, Ch. H., 2009, Adsorption characteristics of Orange II and Chrysophenine on sludge adsorbent and activated carbon fibers, Journal of Hazardous Materials 161, PP.1384-1390

[18] Ndabigengesere, A, Narasiah, S, 1998 Quality of water treated by coagulation using Moringa Oleifera Seeds, Wat. Res,Vol 32,NO 3,PP.781-791

[19] Akhtar, M, Hasany, S. M., Bhanger, M.I., Iqbal,Sh, 2007, Sorption potential of Moringa oleifera pods for the removal of organic pollutants from aqueous solutions, Journal of Hazardous Materials, 141, PP.546-556

[20] Krishna Prasad, R, 2009, Color removal from distillery spent wash through coagulation using Moringa oleifera seeds: Use of optimum response surface methodology, Journal of Hazardous Materials 165, PP. 804-811

[21] Sharma, P, Kumari,P, Srivastava, M. M., Srivastava, Sh, 2006, Removal of cadmium from aqueous system by shelledMoringa oleifera Lam. seed powder, Bioresource Technology 97,PP.299-305

[22] Gupta, V. K., Mittal, A., Krishnan, L., Mittal, J.,2006, Adsorption treatment and recovery of the hazardous dye, Brilliant Blue FCF, over bottom ash and de-oiled soya, J. Colloid Interface Sci. 293, PP.16-26.

[23] Bhatti,H, N, Mumtaz, B, M Asif Hanif, M, Nadeem, R, 2007, Removal of $\mathrm{Zn}$ (II) ions from aqueous solution using Moringa oleifera Lam. (horseradish tree) biomass, Process Biochemistry 42 ,PP. $547-553$

[24] A. Mittal, 2006, Use of hen feathers as potential adsorbent for the removal of a hazardous dye, Brilliant Blue FCF, from wastewater, J. Hazard. Mater. B 128, PP.233-239

[25] M. Nadeem, A. Mahmooda, S. A. Shahid, S. S. Shah, A. M. Khalid, G. McKay,2006, Sorption of lead from aqueous solution by chemically modified carbon adsorbents, J. Hazard. Mater. B 138 ,PP.604-613 